\title{
Persistent Diarrhea in Developing Countries
}

\author{
Zulfiqar A. Bhutta \\ Department of Paediatrics and Child Health, Aga Khan University, Karachi, Pakistan
}

\section{Key Words}

Diarrhea, persistent - Micronutrient deficiency •

Malnutrition · Immune deficiency · Therapy, inappropriate, acute diarrhea

\begin{abstract}
Globally diarrheal diseases account for almost a fifth of all deaths of children under 5 years, with an estimated 2.2 million deaths annually. Of these deaths, a significant proportion are related to episodes of persistent diarrhea (PD; defined as diarrhea of $>14$ days with growth faltering). PD has been shown to identify children with a substantially increased diarrheal burden. These account for $36-54 \%$ of all diarrhea-related deaths. Although the exact pathogenesis of $P D$ remains unclear, most episodes are related to prior acute infectious diarrhea with prolongation of the most recent episode. This may be related to several host factors such as preexisting undernutrition, micronutrient deficiency, immune deficiency and inappropriate therapy of the most recent acute diarrheal episode. The common final event appears to be prolonged intestinal mucosal injury and ineffective repair. In contrast to post-infectious PD, some infants may have severe intractable diarrhea due to a variety of disorders, many of which have a hereditary basis. These now form the dominant type of prolonged diarrhea in developed countries. The management of PD depends upon close attention to nutritional rehabilitation and early recogni-
\end{abstract}

tion of complications. Although a variety of pathogens have been associated with PD, there is little role for oral antimicrobial therapy in the routine treatment of PD. However, attention to rehydration, appropriate screening and treatment of systemic infections and enteral nutrition rehabilitation with easily digestible diets are critical in managing such children, frequently in ambulatory settings. Administration of zinc and vitamin A may shorten the duration of PD and also help reduce recurrences. However, the most important preventive strategies for PD are exclusive breastfeeding in the first 6 months of life, continued breast- feeding for 2 years with appropriate complementary feeding and optimal management of acute diarrheal episodes.

\footnotetext{
Copyright $(2006$ Nestec Ltd., Vevey/S. Karger AG, Basel
}

\section{Introduction}

Despite considerable advances in the understanding and management of diarrheal disorders in childhood, globally these still account for a large proportion (20\%) of childhood deaths, with an estimated 2.2 million deaths [1]. In a global estimate of the burden of diarrheal disorders in 1980 the World Health Organization calculated that there were over 700 million episodes of diarrhea annually in children under 5 years of age in developing countries (excluding China), with approximately 4.6 million deaths [2]. More recent reviews of studies published

\section{KARGER \\ Fax +4161306 1234 E-Mail karger@karger.ch} www.karger.com
(C) 2006 Nestec Ltd., Vevey/S. Karger AG, Basel 0517-8606/06/0641-0039\$23.50/0

Accessible online at:

www.karger.com/ane
Zulfiqar Ahmed Bhutta

Department of Paediatrics and Child Health

Aga Khan University, PO Box 3500, Stadium Road

Karachi 74800 (Pakistan)

Tel. +92 21 4930051/ext. 4724, Fax +92 21 4934294, E-Mail zulfiqar.bhutta@aku.edu 
in the last 10 years indicate that although global mortality may have been reduced, the overall incidence remains unchanged at about 3.2 episodes per child year [2-5]. However, it is important to point out that the amount of information available from good quality epidemiological surveys between these time periods also varied significantly and relatively few studies were conducted recently. The previous survey undertaken in 1993 included 276 studies conducted in 60 countries [3], whereas the 2003 review had data from only 31 studies conducted in 20 countries [5].

It is recognized that most diarrheal disorders form a continuum, with the majority of cases resolving within the first week of illness. However, a smaller proportion of diarrheal illnesses fail to resolve and persist for longer than 2 weeks. Persistent diarrhea (PD) is defined as episodes that began acutely but last for at least 14 days [6]. These criteria identify children with a substantially increased diarrheal burden and an increased rate of diarrhea-related deaths. Such episodes were recognized to account for 3 to $20 \%$ of all diarrheal episodes in children under 5 years of age [7]. In several large community-based studies of diarrhea $[8,9]$ it has been shown that PD is directly responsible for between 36 and 54\% of all diarrhearelated deaths. It has, however, been pointed out that such differences in mortality between different regions may be related to environmental characteristics and differences in the utilization of health care and oral rehydration therapy [10]. Although PD accounted for only 5\% of all diarrheal episodes in a large prospective study of diarrhea in north India, the case fatality rate for PD was $14 \%$ in comparison with $0.7 \%$ for episodes of shorter duration [11].

It is important to recognize that most cases of PD in developing countries represent post-infectious diarrhea. The majority of cases of diarrhea in developing countries are of acute onset and are shorter than 1 week in duration. However, a group of children develop episodes of longer duration, some lasting longer than 14 days [12]. Although the aforementioned division of diarrheal episodes into acute and PD may be arbitrary, this operational definition identifies children with significantly increased diarrheal burdens. In a prospective study in northeastern Brazil, Lima et al. [13] demonstrated that all children with a heavy diarrheal burden (defined as $>16 \%$ of total days spent with diarrhea) had at least one episode of PD during a 1-year study period. Similar observations by Moy et al. [14] in a rural cohort of 204 children in Zimbabwe indicated that although PD accounted for only $6 \%$ of all diarrheal episodes, these included $22 \%$ of the total days of diarrhea recorded in this study and that these children also had higher rates of diarrheal relapse at follow-up. Thus, children with PD may not represent a distinct subgroup but form part of a continuum in susceptibility to diarrhea. Many children (especially infants and toddlers) in developing countries may have frequent recurrent episodes of acute diarrhea. While few individual episodes may persist beyond 14 days, frequent recurrences of acute diarrheal episodes do result in nutritional compromise and may predispose these children to develop PD.

In contrast to PD in developing countries, cases of prolonged diarrhea among young children in developed countries may fall under the category of intractable diarrhea of infancy. These cases are defined as diarrhea lasting for at least 2 weeks where at least $50 \%$ of the daily fluid requirement may need to be provided intravenously. Many of these disorders have a genetic basis and may also be seen in developing countries, although their prevalence is greatly overshadowed by those of post-infectious PD.

\section{Review Methods}

A recent working group on PD reviewed the information and actions needed at the level of pediatricians, training institutions and professional societies [15]. However, the review did not elaborate upon recent epidemiological trends, and interventions needed in public health systems. This current review will present an overview of the current status of epidemiological information and evidence gaps for clinical care as well as public health interventions.

In order to assess recently available information and trends, we reviewed all the available information on diarrhea epidemiology and PD over the last 15 years (19902004) in electronic medical (PubMed/Medline, Extra Med, Pop Line) and social science libraries. Other search terms such as 'chronic diarrhea', 'prolonged diarrhea' and 'intractable diarrhea' also were used to search for published relevant reports. In addition a manual search of relevant monographs and WHO/UNICEF materials also was conducted to access recent information on PD and management strategies targeting children. The available studies were then classified into those addressing epidemiology or burden estimates, pathogenesis, management strategies at either facility or community settings and available randomized controlled trials. We also evaluated studies of PD that related to the HIV status of populations and related pathogens such as cryptosporidium, Giardia lamblia, etc. 


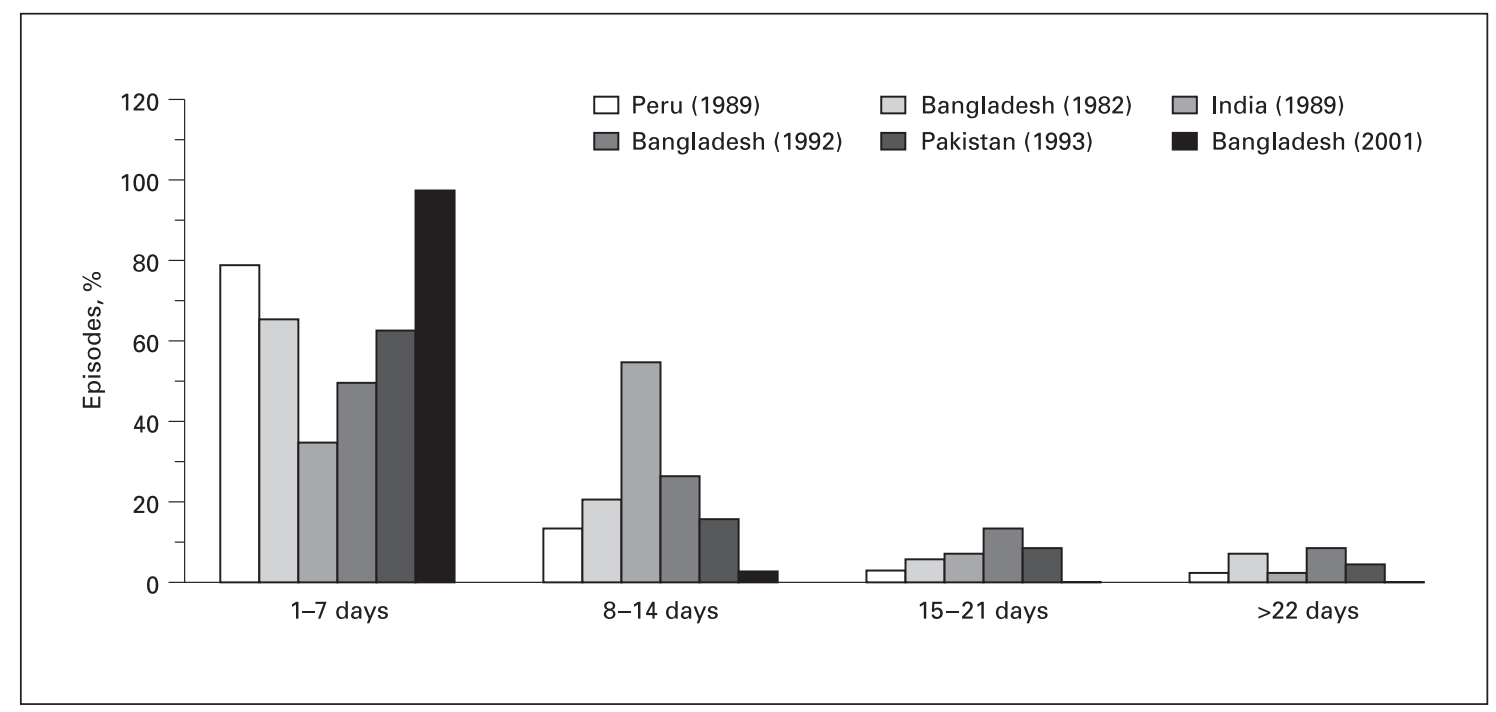

Fig. 1. Incidence of childhood diarrhea in community settings [11, 17-20].

It was evident that the bulk of the epidemiological information on the relationship of acute diarrheal episodes to PD was derived from studies undertaken over a decade ago. There was a remarkable paucity of recent data on this subject, especially from non-HIV endemic areas. However, it was evident from studies in HIV endemic areas that chronic enteropathy and PD was increasingly recognized as common manifestations of advancing HIV infection and AIDS [16].

There is little evidence overall that the true global incidence of PD has decreased. Figure 1 indicates the duration of diarrhea from several community-based studies in developing countries [11,17-20]. Although recent data from community-based studies on diarrhea are relatively sparse, the overall rates of PD from community settings appeared remarkably constant over the period between 1980 and 1992. A recent community-based study from Bangladesh [20] indicates that PD accounted for less than $0.5 \%$ of all cases of diarrhea in an urban community setting, and it is difficult to generalize about trends in the reduction of the burden of PD. There is a clear need to review the previously estimated proportions of acute diarrheal episodes that become prolonged.

The HIV/AIDS epidemic in Africa has resulted in a change in the usual etiological patterns of diarrhea. Prolonged episodes associated with infections due to relatively rare organisms such as cryptosporidium are more common.

\section{Pathogenesis of PD}

Prolonged diarrhea in childhood also may arise from a large number of conditions, many of them non-infectious. The most common of these disorders are: cow/soy milk protein intolerance (in infants $<6$ months old, often with blood-tinged stools); celiac disease (gluten-sensitive enteropathy), and cystic fibrosis (creatorrhea and steatorrhea secondary to pancreatic insufficiency). In other instances, toddler's diarrhea also may be seen in relatively well-nourished infants.

However, globally the most important underlying trigger for PD is an acute diarrheal episode due to an enteric infection and the consequences thereof. There have been several studies on pathogens causing PD in developing countries but few have pinpointed a major causative organism. Although it may appear that PD is a consequence of poor management of acute infectious diarrhea, some pathogens are isolated with greater frequency from children with PD. Table 1 indicates the various organisms that have been associated with PD among children from different parts of the world.

Globally almost a quarter of all diarrhea deaths are associated with dysentery, a large proportion caused by Shigella organisms. In a recent study from Bangladesh [21], PD was seen in $23 \%$ of children with shigellosis and Shigella infections were significantly associated with an increased risk of PD (age-adjusted relative risk 1.83; 95\% confidence interval 1.19-2.81). Infection by multiple an- 
Table 1. Pathogens associated with prolonged and persistent diarrhea

\begin{tabular}{ll}
\hline Bacteria & Enteroaggregative Escherichia coli \\
& Enteropathogenic Escherichia coli \\
& Campylobacter \\
& Salmonella enteritides \\
& Shigella species \\
& Clostridium difficile \\
& Arcobacter butzleri \\
& Klebsiella species \\
\hline Parasites & Giardia lamblia \\
& Blastocystis hominis ${ }^{1}$ \\
& Cryptosporidium spp. $^{1}$ \\
& Entamoeba histolytica \\
& Cyclospora cayetanensis ${ }^{1}$ \\
\hline Viruses & Human astrovirus 3 \\
& Enterovirus \\
& Picobernaviruses \\
\hline
\end{tabular}

${ }^{1}$ Especially associated with HIV infections/AIDS.

Table 2. Etiology of intractable diarrhea of infancy

1 Congenital chloride diarrhea

2 Microvillus inclusion disease

3 Epithelial dysplasia or Tufting enteropathy

4 Autoimmune enteropathy

5 Food allergy

6 Chronic intestinal pseudo-obstruction/Hirschsprung's disease

7 Intestinal lymphangiectasia

8 Abeta-lipoproteinemia

9 Eosinophilic enteropathy

10 Intestinal neurodysplasia

11 Congenital enzymatic deficiency (congenital glucosegalactose malabsorption, sucrase-isomaltase deficiency, etc.)

12 Trichorrhexis nodosa, facial dysmorphism, immune deficiency and cirrhosis

tibiotic-resistant Shigella isolates (age-adjusted relative risk 3.76; 95\% confidence interval 1.51-9.36) and occurrence of shigellosis during infancy were observed to be risk factors for initiation of Shigella diarrhea persistence. However, $88 \%$ of the persistent shigellosis episodes occurred in older children, 50\% were associated with nondysenteric shigellosis and 79\% were caused by Shigella species other than Shigella dysenteriae. Other organisms may similarly affect mucosal inflammation. An additional pathogenic mechanism underlying entero-aggregative
Escherichia coli infections may include the induction of IL-8 and mucosal inflammation.

In contrast to $\mathrm{PD}$, there is much greater understanding of the mucosal absorptive and transport mechanisms underlying intractable diarrhea in developed countries. Table 2 indicates some of the major causes of intractable diarrhea of infancy.

It is now recognized that mutations of the $\mathrm{Cl}^{-} / \mathrm{HCO}_{3}^{-}$ exchanger of the ileocolonic apical membrane (solute carrier family 26, member 3 gene [SLC26A3, alias CLD or DRA]) result in the net secretion of chloride by the intestine and a clinical syndrome recognized as congenital chloride-losing diarrhea [22]. Similarly it is recognized that congenital glucose/galactose malabsorption is the result of a genetic defect resulting in a reduction or absence of functional sodium-coupled glucose transporter SGLT1 at the enterocyte cell surface [23], and a number of genotype/phenotype relationships have been recognized [24]. Congenital sucrase-isomaltase deficiency (CSID) also presents with osmotic diarrhea following the introduction of sucrose/complex starches into the weaning diet. Molecular and cell biological studies have defined the pathogenesis of CSID extremely well demonstrating that CSID appears to be a result both of defective synthesis and glycoprotein processing [25].

In contrast, detailed studies from developing countries of mucosal abnormalities and factors underlying mucosal abnormalities in PD are woefully rare and none have explored the molecular mechanisms of prolonged intestinal injury. The most striking example of the critical role that the immune system plays in the pathogenesis of PD is the relationship of HIV/AIDS with PD. This is exemplified by a host of studies linking PD with cryptosporidiosis [26] and other parasitic infections in Africa and Asia. Although these observations suggest that immune deficiency may be related to the risk of prolonged diarrhea [27], there also has been much interest in the possibility that a transient immune deficiency also may be a marker of concomitant micronutrient deficiency $[28,29]$.

An additional factor underlying poor intestinal repair may include key micronutrient deficiencies that can influence this process. From initial studies indicating the potential benefit of zinc supplementation on reducing the risk of prolonged diarrhea [30], recent meta-analyses of zinc supplementation in diarrheal illnesses indicate a significant reduction in the duration and severity of diarrheal illnesses [31]. Thus zinc deficiency may significantly contribute to the prolongation of mucosal injury and delayed intestinal repair mechanisms. The benefits of 


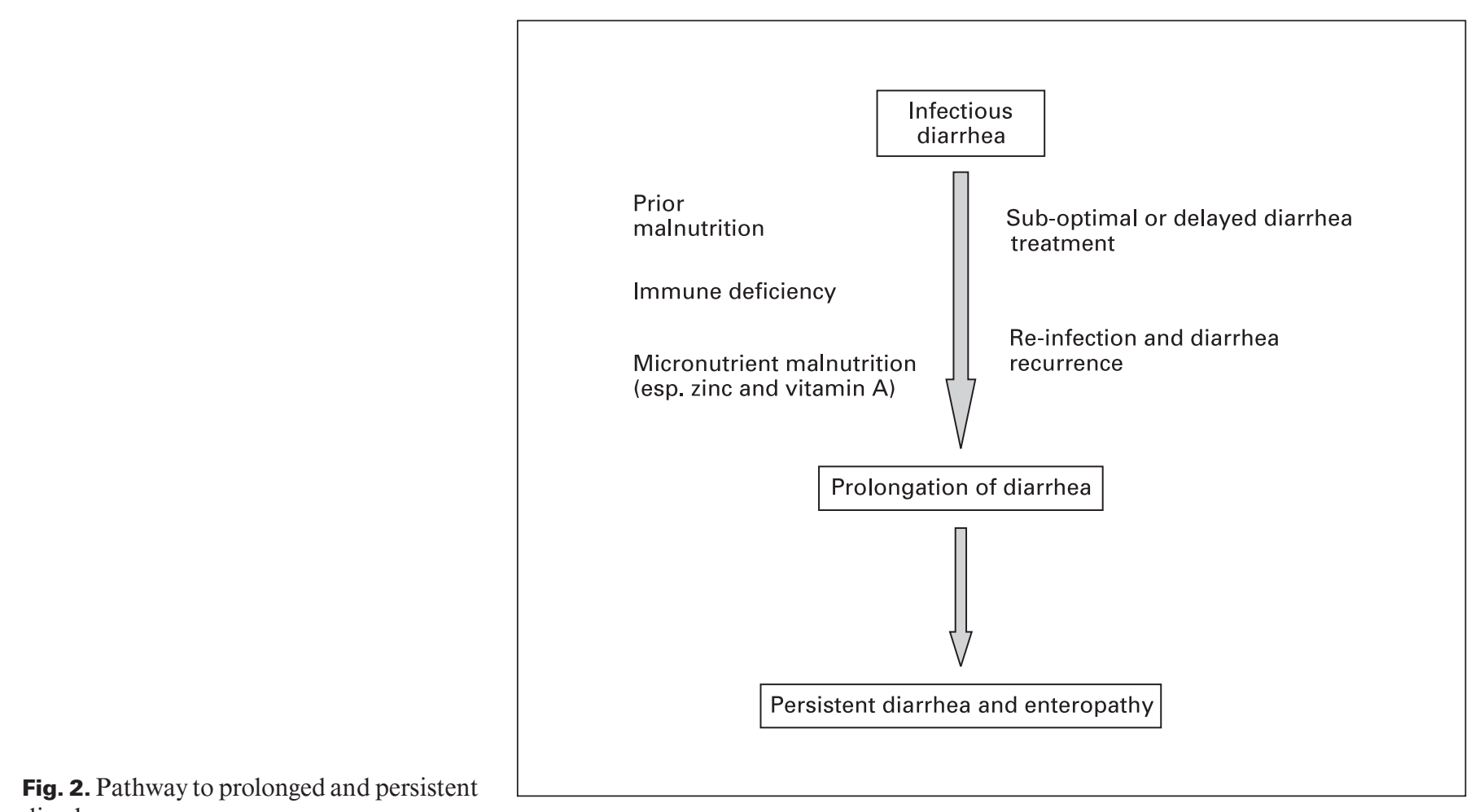
diarrhea.

zinc in reducing mortality from childhood diarrhea have led to its inclusion in the current recommendations for diarrhea management by WHO/UNICEF [32]. However, very little is known about the mechanisms of action of zinc in reducing diarrhea duration and severity and maintaining intestinal mucosal integrity.

Poor intestinal repair is regarded as a key component of abnormal mucosal morphology. However, the exact factors underlying ineffective repair processes and continuing injury are understood poorly. The end result of mucosal derangement is poor absorption of luminal nutrients and increased permeability of the bowel to dietary or microbial antigens. Although PD is recognized widely as a nutritional disorder, there is remarkably poor understanding of the mechanisms underlying PD and the mucosal immunopathology in children who develop this syndrome. However, several factors that contribute to diarrheal persistence have been recognized, including general undernutrition, and micronutrient and immune deficiencies, suggesting that delayed intestinal repair following initial injury may be an important contributory factor. Figure 2 indicates the mechanisms associated with delayed intestinal repair and prolonged enteropathy that may underlie post-infectious PD.

Persistent Diarrhea in Developing Countries
A clear understanding of the alterations in intestinal morphology and physiology is crucial to the development of interventional strategies. However, a wide variety of post-PD pathological changes have been described by fairly small studies [33-35]. These studies indicate important findings suggestive of chronic inflammation and impaired mucosal integrity. In this regard there needs to be much more concerted work on representative populations.

\section{Management of PD}

The most important aspect in the management of the child with PD is an immediate assessment and triage for subsequent therapy. The management of PD in undernourished children is based on the principles of management of diarrhea and undernutrition. Although a subgroup may be severely undernourished requiring rapid nutritional rehabilitation, often in hospital, in other cases ambulatory management may be possible. Given the long time it may take to recovery, prolonged hospitalization may be quite problematic in developing countries, and whenever possible ambulatory or home-based therapy must be stressed. 


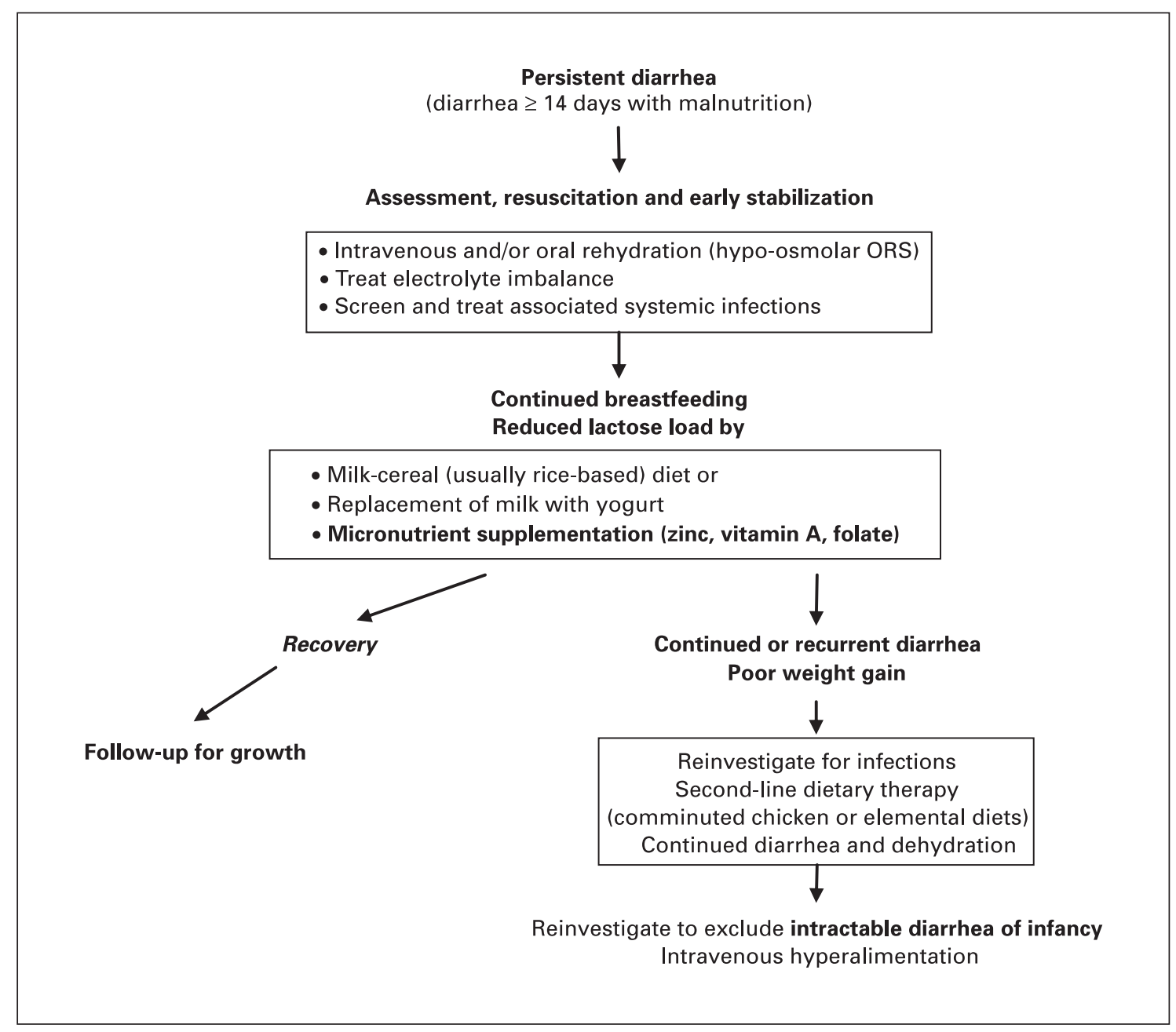

Fig. 3. Suggested algorithm for the management of persistant diarrhea.

The following represent the basic principles of management of PD and a suggested therapeutic approach is summarized in figure 3 [36].

\section{(1) Initial Resuscitation and Stabilization}

Most children with PD and associated undernutrition are not severely dehydrated and oral rehydration may be adequate. However, acute exacerbations and associated vomiting may require brief periods of intravenous rehydration with Ringer's lactate. Acute electrolyte imbalances such as hypokalemia and severe acidosis may require correction. More importantly, bacterial translocation [37] and systemic infections have been recognized in severely undernourished children with PD and are a frequent cause of early mortality. These must be screened for on admission. Up to half of all undernourished chil- dren with PD may have an associated systemic infection requiring resuscitation and antimicrobial therapy [38, 39]. In severely ill undernourished children requiring hospitalization, broad-spectrum antibiotics on initial admission and stabilization may be required while awaiting cultures. Some may also require empirical therapy for cryptosporidiosis, especially in HIV-infected children [40].

\section{(2) Oral Rehydration Therapy}

Although in general the standard WHO oral rehydration solution is adequate for replacing on-going losses, recent evidence indicates that low osmolality oral rehydration fluids [41, 42] may be advantageous in undernourished children, with no associated risk of hyponatremia. 


\section{(3) Enteral Feeding and Diet Selection}

It is exceedingly rare to find PD in exclusively breastfed infants and, with the context specific possible exceptions of situations where PD accompanies perinatally acquired HIV infection, breastfeeding must be continued.

Despite mucosal abnormalities and diminution in digestive and absorptive mechanisms, most children with PD have adequate absorption capacity and tolerate enteral feedings. Metabolic balance studies in undernourished children with PD indicate that satisfactory carbohydrate, protein and fat absorption can take place on a variety of diets [43, 44]. In general, therefore, withdrawal of milk and replacement with specialized (and expensive) lactose-free formulations is unnecessary.

Most children with PD are not lactose intolerant, although administration of lactose loads exceeding $5 \mathrm{~g} / \mathrm{kg} /$ day are associated with higher purging rates and treatment failures [45]. Alternative strategies of reducing lactose loads in undernourished children with PD include addition of milk to cereals and replacement of milk with fermented milk products such as yogurt. These dietary interventions have been evaluated extensively in several studies, and found to be efficacious and acceptable in comparison to several expensive formulations [7, 46].

Rarely when dietary intolerance precludes the administration of cow's milk-based formulations or cow's milk, it may be necessary to administer specialized milk-free diets such as a comminuted or blenderized chicken-based diet or an elemental formulation [47]. It must be pointed out that although effective in some settings [48], the latter are unaffordable in most developing countries. However, a guar gum-comminuted chicken combination has been found to be effective in children with PD [49]. In addition to the above, the addition of green banana or pectin to the diet [50] has been shown to be effective in the treatment of PD.

The usual energy density of any diet used for the therapy of PD should be around $1 \mathrm{kcal} / \mathrm{g}$, aiming to provide an energy intake of at least $100 \mathrm{kcal} / \mathrm{kg} / \mathrm{day}$, and a protein intake of between 2 and $3 \mathrm{~g} / \mathrm{kg} /$ day. The commonly used rice-lentil formulations in South Asia such as khitchri provide this energy density in combination with an optimal protein intake and amino acid ratio.

\section{(4) Micronutrient Supplementation}

It is recognized widely that most undernourished children with PD have associated deficiencies of micronutrients including zinc, iron and vitamin A. This may be a consequence of poor intake and continued enteral losses and requires replenishment during therapy [51]. Although the evidence supporting zinc administration in children with PD is persuasive, it is likely that these children have multiple micronutrient deficiencies. Concomitant vitamin A administration to children with PD was shown to improve outcomes [52, 53], especially in HIV endemic areas [54]. It is therefore important to ensure that all children with PD and undernutrition receive an initial dose of 100,000 units vitamin A and a daily intake of at least $3-5 \mathrm{mg} / \mathrm{kg} /$ day of elemental zinc.

\section{(5) Follow-Up and Nutritional Rehabilitation in Community Settings}

Given the high rates of relapse in most children with $\mathrm{PD}$, it is important to address the underlying risk factors and institute preventive measures. These include appropriate feeding (breastfeeding and complementary feeding) and close attention to environmental hygiene and sanitation. This poses a considerable challenge in communities deprived of basic necessities such as clean water and sewage disposal.

In addition to preventive aspects, the challenge in most settings is to develop and sustain a form of dietary therapy using inexpensive, home-available and culturally acceptable ingredients that can be used to manage children with PD. Given that the majority of cases of PD occur in the community and that parents frequently are hesitant to seek institutional help, there is a need to develop and implement inexpensive and practical homebased therapeutic measures. Available evidence indicates that it may be entirely feasible to do so in community settings $[55,56]$.

\section{Preventive Strategies for PD}

Although optimal nutritional rehabilitation of children with PD is regarded as a cornerstone of management [44], prevention is critical. For this purpose large-scale improvements in diarrhea prevention and management strategies in developing countries are critical. As indicated by us in reviewing available child survival interventions, existing interventions can prevent almost $55 \%$ of all deaths globally in children under 5 years [57], a fifth of which are related to diarrhea.

These interventions include exclusive breastfeeding and safe complementary feeding strategies to prevent diarrhea and, in the event episodes occur, optimal management with improved oral rehydration, zinc supplementation and continued feeding. As indicated above, this re- 
quires that all episodes of diarrhea are recognized promptly and managed optimally with oral rehydration and enteral feeding with inexpensive, home-available and culturally acceptable diets that can be used to manage children with PD in ambulatory settings. The next steps would be to integrate these interventions so that families and community health workers can implement them in a variety of situations [58].

Providing essential preventive and therapeutic interventions to reduce PD in health systems are necessary in order to achieve the millennium development goals of reducing child mortality by two thirds by the year 2015 . Early and unhygienic introduction of milks other than breast milk and recurrent acute diarrheal episodes that are managed poorly are important predisposing factors to the development of PD. It is important that these be prevented. These risk factors are generally prevalent in poor communities and both poverty alleviation and social sector support mechanisms are fundamentally im- portant. Thus promotion of exclusive breastfeeding for at least 6 months, avoidance of unhygienic formula feeding, timely and adequate weaning with hygienic nutritious foods will help to prevent episodes of post-infectious PD. These must be coupled with environmental control measures and provision of safe water and safe foods [59]. In the absence of the latter, interventions to promote handwashing strategies and domestic measures to purify water are key to reducing the burden of diarrhea $[60,61]$.

A combination of allocation of appropriate resources for public health and basic needs, staff training and community mobilization are necessary to reduce the global burden of diarrhea and PD. This requires sustained and concerted efforts. In many parts of the developing world these interventions require that, apart from biomedical interventions, we give paramount importance to poverty alleviation and promotion of a human rights and equity agenda.

\section{References}

$\checkmark 1$ Black RE, Morris SS, Bryce J: Where and why are 10 million children dying every year? Lancet 2003;361:2226-2234.

-2 Snyder JD, Merson MH: The magnitude of the global problem of acute diarrheal disease: a review of active surveillance data. Bull World Heath Organ 1982;60:605-613.

-3 Bern C, Martines J, de Zoysa I, Glass RI: The magnitude of the global problem of diarrhoeal disease: a ten-year update. Bull World Health Organ 1992;70:705-714.

4 Yusufzai M, Bhutta ZA: Global burden of childhood diarrhea; in Bhutta ZA (ed): Contemporary Issues in Childhood Diarrhea and Malnutrition. Karachi, Oxford University Press, 2000, pp 1-22.

5 Kosek M, Bern C, Guerrant RL: The global burden of diarrheal disease as estimated from studies published between 1990 and 2000. Bull World Health Organ 2003;81:197-2004.

6 Anonymous: Persistent diarrhoea in children in developing countries: memorandum from a WHO Meeting. Bull World Health Organ 1988;66:709-717

7 Anonymous: Evaluation of an algorithm for the treatment of persistent diarrhoea: a multicentre study. International Working Group on Persistent Diarrhoea. Bull World Health Organ 1996;74:479-489.

-8 Schorling JB, Wanke CA, Schorlling SK, McAullife JF, de Souza MA, Guerrat RL: A prospective study of persistent diarrhea among children in an urban Brazilian slum: patterns of occurrence and etiologic agents. Am J Epidemiol 1990;132:144-156.
9 Fauveau V, Henry FJ, Briend A, Yunus M, Chakraborty J: Persistent diarrhea as a cause of childhood mortality in rural Bangladesh. Acta Paediatr Suppl 1992;381:12-14.

10 Victora CG, Huttly SRA, Fuch SC, et al: International differences in clinical patterns of diarrhoeal deaths: a comparison of children from Brazil, Senegal, Bangladesh and India. J Diarrhoeal Dis Res 1993;11:25-29.

11 Bhan MK, Bhandari N, Sazawal S, Clemens J, Raj P: Descriptive epidemiology of persistent diarrhoea among young children in rural northern India. Bull World Health Organ 1989;67:281-288.

12 Black RE: Persistent diarrhea in children of developing countries. Pediatr Infect Dis J 1993; 12:751-761.

13 Lima AAM, Fang G, Schorling JB, Albuquerque L, Mc Aulliffe JA, Mota S, Leite R, Guerrant RL: Persistent diarrhea in northeast Brazil: etiologies and interaction with malnutrition. Acta Paediatr SuppI 1992;381:39-44.

14 Moy RJ, Booth IW, Choto R-G, McNeish AS: Recurrent and persistent diarrhoea in a rural Zimbabwean community: a prospective study. J Trop Pediatr 1991;37:293-299.

15 Bhutta ZA, Ghishan F, Lindley K, Memon IA, Mittal S, Rhoads JM: Persistent and chronic diarrhea and malabsorption: Working Group report of the second World Congress of Pediatric Gastroenterology, Hepatology, and $\mathrm{Nu}-$ trition. J Pediatr Gastroenterol Nutr 2004; (suppl 2):S711-S716.

16 Adejuyigbe EA, Oyelami O, Onayemi O, Durosinmi MA: Paediatric HIV/AIDS in Ile-Ife, Nigeria. Cent Afr J Med 2003;49:74-78.
17 Black RE, Brown KH, Becker S, Yunus M: Longitudinal studies of infectious diseases and physical growth of children in rural Bangladesh. I. Patterns of morbidity. Am J Epidemiol 1982;115:305-314.

18 Lanata CF, Black RE, Gilman RH, Lazo F, Del Aguila R: Epidemiologic, clinical, and laboratory characteristics of acute vs persistent diarrhea in periurban Lima, Peru. J Pediatr Gastroenterol Nutr 1991;12:82-88.

19 Mahmud A, Jalil F, Karlberg J, Lindblad BS: Early child health in Lahore, Pakistan: VII. Diarrhoea. Acta Paediatr Suppl 1993;390:7985.

20 Haque R, Monda Dl, Kirkpatrick BD, Akther Farr BM, Sack RB, Petri WB Jr: Epidemiologic and clinical characteristics of acute diarrhea with emphasis on Entamoeba histolytica infections in preschool children in an urban slum of Dhaka, Bangladesh. Am J Trop Med Hyg 2003;69:398-405.

-21 Ahmed F, Ansaruzzaman M, Haque E, Rao MR, Clemens JD: Epidemiology of postshigellosis persistent diarrhea in young children. Pediatr Infect Dis J 2001;20:525-530.

22 Hoglund P, Haila S, Socha J, Tomaszewski L, Saarialho-Kere U, Karjalainen-Lindsberg ML, Airola K, Holmberg C, de la CA, Kere J: Mutations of the Down-regulated in adenoma (DRA) gene cause congenital chloride diarrhoea. Nat Genet 1996;14:316-319.

23 Turk E, Zabel B, Mundlos S, Dyer J, Wright EM: Glucose/galactose malabsorption caused by a defect in the $\mathrm{Na}+$ /glucose cotransporter. Nature 1991;350:354-356. 
-24 Martin MG, Turk E, Lostao MP, Kerner C, Wright EM: Defects in Na+/glucose cotransporter (SGLT1) trafficking and function cause glucose-galactose malabsorption. Nat Genet 1996;12:216-220.

-25 Naim HY, Roth J, Sterchi EE, Lentze M, Milla P, Schmitz J, Hauri HP: Sucrase-isomaltase deficiency in humans. Different mutations disrupt intracellular transport, processing, and function of an intestinal brush border enzyme. J Clin Invest 1988;82:667-679.

-26 Amadi B, Kelly P, Mwiya M, Mulwazi E, Sianongo $\mathrm{S}$, Changwe $\mathrm{F}$, Thomson $\mathrm{M}$, Hachungula J, Watuka A, Walker-Smith J, Chintu C: Intestinal and systemic infection, HIV, and mortality in Zambian children with persistent diarrhea and malnutrition. J Pediatr Gastroenterol Nutr 2001;32:550-554.

-27 Baqui A H, Black R E, Sack R B, Chowdhury HR, Yunus M, Siddique A K: Malnutrition, cell-mediated immune deficiency and diarrhea: a community-based longitudinal study in rural Bangladeshi children. Am J Epidemiol 1993; 137:355-365.

28 Azim T, Ahmad SM, Sefat-E-Khuda, Sarker MS, Unicomb LE, De S, Hamadani JD, Salam MA, Wahed MA, Albert MJ: Immune response of children who develop persistent diarrhea following rotavirus infection. Clin Diagn Lab Immunol 1999;6:690-695.

-29 Taniguchi K, Rikimaru T, Yartey JE, Akpedonu P, Armar-Klemesu MA, Nkrumah FK, Kamiya H, Kishi K, Armar DA: Immunological background in children with persistent diarrhea in Ghana. Pediatr Int 1999;4:162167.

- 30 Sazawal S, Black R E, Bhan M K, Bhandari N, Sinha A, Jalla S: Zinc supplementation in young children with acute diarrhea in India. $\mathrm{N}$ Engl J Med 1995;333:839-844.

31 Bhutta ZA, Bird SM, Black RE, Brown KH, Gardner JM, Hidayat A, Khatun F, Martorell R, Ninh NX, Penny ME, Rosado JL, Roy SK, Ruel M, Sazawal S, Shankar A: Therapeutic effects of oral zinc in acute and persistent diarrhea in children in developing countries: pooled analysis of randomized controlled trials. Am J Clin Nutr 2000;72:1516-1522.

32 WHO/UNICEF Joint Statement: Clinical Management of Acute Diarrhea. May 2004. http://www.mostproject.org/ZINC/WHOUNICEF/Statement.pdf (accessed Feb 27, 2005).

33 Sullivan PB: Studies of the small intestine in persistent diarrhea and malnutrition: the Gambian experience. J Pediatr Gastroenterol Nutr 2002;34(suppl 1):S11-S13.

-34 Campbell DI, Murch SH, Elia M, Sullivan PB, Sanyang MS, Jobarteh B, Lunn PG: Chronic T cell-mediated enteropathy in rural west African children: relationship with nutritional status and small bowel function. Pediatr Res 2003;54:306-311.

- 35 Fagundes-Neto U, De Martini-Costa S, Pedroso MZ, Scaletsky IC: Studies of the small bowel surface by scanning electron microscopy in infants with persistent diarrhea. Braz J Med Biol Res 2000;33:1437-1442.
36 Bhutta ZA: Persistent diarrhea; in Guandalini $\mathrm{S}$ (ed): Text Book of Gastroenterology. London, Taylor \& Francis, 2004.

37 Campbell DI, Elia M, Lunn PG: Growth faltering in rural Gambian infants is associated with impaired small intestinal barrier function, leading to endotoxemia and systemic inflammation. J Nutr 2003; 133:1332-1338.

38 Bhutta ZA, Nizami SQ, Thobani S: Factors determining recovery during nutritional therapy of persistent diarrhoea: the impact of diarrhoea severity and intercurrent infections. Acta Paediatr 1997;86:796-802.

>39 Alam NH, Faruque AS, Dewan N, Sarker SA, Fuchs GJ: Characteristics of children hospitalized with severe dehydration and persistent diarrhoea in Bangladesh. J Health Popul Nutr 2001;19:18-24.

40 Amadi B, Mwiya M, Musuku J, Watuka A, Sianongo S, Ayoub A, Kelly P: Effect of nitazoxanide on morbidity and mortality in Zambian children with cryptosporidiosis: a randomised controlled trial. Lancet 2002;360: 1375-1380.

41 Sarker SA, Mahalanabis D, Alam NH, Sharmin S, Khan AM, Fuchs GJ: Reduced osmolarity oral rehydration solution for persistent diarrhea in infants: a randomized controlled clinical trial. J Pediatr 2001;138:532-538.

42 Dutta P, Mitra U, Dutta S, Manna B, Chatterjee MK, De A, Bhattacharya SK: Hypo-osmolar oral rehydration salts solution in dehydrating persistent diarrhoea in children: double-blind, randomized, controlled clinical trial. Acta Paediatr 2000;89:411-416.

43 Bhutta ZA, Molla AM, Isani Z, Badruddin S, Hendricks K, Snyder JD: Dietary management of persistent diarrhea: comparison of a traditional rice-lentil based diet with soy formula. Pediatrics 1991;88:1010-1018.

44 Bhutta ZA, Hendricks KH: Nutritional management of persistent diarrhea in childhood: a perspective from the developing world. J Pediatr Gastroenterol Nutr 1996;22:17-37.

45 Penny ME, Paredes P, Brown KH: Clinical and nutritional consequences of lactose feeding during persistent postenteritis diarrhea. Pediatrics 1989;84:835-844.

46 Ashraf H, Ahmed S, Fuchs GJ, Mahalanabis D: Persistent diarrhoea: associated infection and response to a low lactose diet. J Trop Pediatr 2002;48:142-148.

47 Godard C, Bustos M, Munoz M, Nussle D: Value of a chicken-based formula for refeeding of children with protracted diarrhea and malnutrition in a developing country. J Pediatr Gastroenterol Nutr 1989;9:473-480.

48 Amadi B: Role of food antigen elimination in treating children with persistent diarrhea and malnutrition in Zambia. J Pediatr Gastroenterol Nutr 2002;34(suppl 1):S54-S56.
49 Alam NH, Meier R, Sarker SA, Bardhan PK, Schneider H, Gyr N: Partially hydrolysed guar gum supplemented comminuted chicken diet in persistent diarrhoea: a randomised controlled trial. Arch Dis Child 2005;90:195199.

50 Rabbani GH, Teka T, Zaman B, Majid N, Khatun M, Fuchs GJ: Clinical studies in persistent diarrhea: dietary management with green banana or pectin in Bangladeshi children. Gastroenterology 2001;121:554-560.

51 Mahalanabis D, Bhan MK: Micronutrients as adjunct therapy of acute illness in children: impact on the episode outcome and policy implications of current findings. Br J Nutr 2001; 85(suppl 2):S151-S158.

52 Rahman MM, Vermund SH, Wahed MA, Fuchs GJ, Baqui AH, Alvarez JO: Simultaneous zinc and vitamin A supplementation in Bangladeshi children: randomised double blind controlled trial. BMJ 2001;323:314318.

53 Khatun UH, Malek MA, Black RE, Sarkar NR, Wahed MA, Fuchs G, Roy SK: A randomized controlled clinical trial of zinc, vitamin A or both in undernourished children with persistent diarrhea in Bangladesh. Acta Paediatr 2001;90:376-380.

54 Villamor E, Mbise R, Spiegelman D, Hertzmark E, Fataki M, Peterson KE, Ndossi G, Fawzi WW: Vitamin A supplements ameliorate the adverse effect of HIV-1, malaria, and diarrheal infections on child growth. Pediatrics 2002;109:E6.

55 Bhandari N, Bahl R, Saxena M, Taneja S, Bhan MK: Prognostic factors for persistent diarrhoea managed in a community setting. Indian J Pediatr 2000;67:739-745.

-56 Valentiner-Branth P, Steinsland H, Santos G, Perch M, Begtrup K, Bhan MK, Dias F, Aaby $\mathrm{P}$, Sommerfelt H, Molbak K: Communitybased controlled trial of dietary management of children with persistent diarrhea: sustained beneficial effect on ponderal and linear growth. Am J Clin Nutr 2001;73:968-974.

57 Jones G, R Steketee RW, Black RE, Bhutta ZA, Morris SS and the Bellagio Child Survival Study Group: How many child deaths can we prevent this year? Lancet 2003;362:65-71.

58 Travis $\mathrm{P}$, Bennett $\mathrm{S}$, Haines A, Pang T, Bhutta Z A, Hyder AA, Pielemeier NR, Mills A, Evans $\mathrm{T}$ : Overcoming health-systems constraints to achieve the Millennium Development Goals. Lancet 2004;364:900-906.

59 Sheth M, Obrah M: Diarrhea prevention through food safety education. Indian J Pediatr 2004;71:879-882.

60 Curtis V, Cairncross S: Effect of washing hands with soap on diarrhoea risk in the community: a systematic review. Lancet Infect Dis 2003;3: 275-281.

61 Luby SP, Agboatwalla M, Painter J, Altaf A, Billhimer WL, Hoekstra RM: Effect of intensive handwashing promotion on childhood diarrhea in high-risk communities in Pakistan: a randomized controlled trial. JAMA 2004;291: 2547-2554. 